University of Wollongong

Research Online

Faculty of Health and Behavioural Sciences -

Papers (Archive)

Faculty of Science, Medicine and Health

$1-1-2008$

\title{
Toward the science-informed practice of clinical supervision: the Australian context
}

Craig J. Gonsalvez

University of Wollongong, craigg@uow.edu.au

Hamish McLeod

hamish@uow.edu.au

Follow this and additional works at: https://ro.uow.edu.au/hbspapers

Part of the Arts and Humanities Commons, Life Sciences Commons, Medicine and Health Sciences Commons, and the Social and Behavioral Sciences Commons

\section{Recommended Citation}

Gonsalvez, Craig J. and McLeod, Hamish: Toward the science-informed practice of clinical supervision: the Australian context 2008, 79-87.

https://ro.uow.edu.au/hbspapers/1871

Research Online is the open access institutional repository for the University of Wollongong. For further information contact the UOW Library: research-pubs@uow.edu.au 


\title{
Toward the science-informed practice of clinical supervision: the Australian context
}

\begin{abstract}
Although supervision of clinical practice is mandatory for trainee psychologists, surprisingly little is known about the key ingredients of effective supervision and the relationship between supervision and patient outcomes. The purpose of this paper was to review current regulations that shape supervision in Australia and explore the links between these regulations and the components of effective supervision. Although recent developments including supervisor training and other quality control programs are an indication of progress, there are several empirical and conceptual issues in the supervision literature that require resolution. The second part of this paper identifies the gaps in the supervision literature and suggests steps to advance the development of a mature science of clinical supervision. The main areas requiring attention include the identification of the mechanisms by which supervision produces change in supervisees and their patients, the refinement of measurement methods and instrumentation, and the need to pursue collaborative research that maximises the generalisability of research findings.
\end{abstract}

\section{Keywords}

Toward, science, informed, practice, clinical, supervision, Australian, context

\section{Disciplines}

Arts and Humanities | Life Sciences | Medicine and Health Sciences | Social and Behavioral Sciences

\section{Publication Details}

Gonsalvez, C. J. \& McLeod, H. J. (2008). Toward the science-informed practice of clinical supervision: the Australian context. Australian Psychologist, 43 (2), 79-87. 


\title{
Toward the science-informed practice of clinical supervision: The Australian context
}

\author{
CRAIG J. GONSALVEZ \& HAMISH J. MCLEOD
}

School of Psychology and Illawarra Institute for Mental Health, University of Wollongong, Wollongong, New South Wales, Australia

\begin{abstract}
Although supervision of clinical practice is mandatory for trainee psychologists, surprisingly little is known about the key ingredients of effective supervision and the relationship between supervision and patient outcomes. The purpose of this paper was to review current regulations that shape supervision in Australia and explore the links between these regulations and the components of effective supervision. Although recent developments including supervisor training and other quality control programs are an indication of progress, there are several empirical and conceptual issues in the supervision literature that require resolution. The second part of this paper identifies the gaps in the supervision literature and suggests steps to advance the development of a mature science of clinical supervision. The main areas requiring attention include the identification of the mechanisms by which supervision produces change in supervisees and their patients, the refinement of measurement methods and instrumentation, and the need to pursue collaborative research that maximises the generalisability of research findings.
\end{abstract}

Keywords: Professional development, professional supervision, training in psychology.

The current paper has two main aims: (a) to provide a snapshot of clinical supervision in Australia including recent developments; and (b) to outline key lacunae in the research literature on clinical supervision, highlighting areas considered critical to the advancement of the scientific practice of clinical supervision. Where applicable, the comments are tailored to the Australian context. Also, the article primarily relates to supervision of psychologists providing assessment and treatment to people with mental health problems. But because supervision of psychological practice is a mandatory aspect of training for psychologists in diverse fields ranging from business to health care, our discussion at times includes comparisons of these subspecialties. The terms "supervision" and "clinical supervision" are used in a generic sense to cover professional supervision across specialisations in psychology and across early stages of professional development, applying to supervision both before and after psychologist registration. The article does not address professional consultation, which refers to a relationship among equals and which lacks the evaluative component typical of supervision.

\section{Supervision of Australian psychologists in 2007}

Supervision standards for Australian psychologists are primarily regulated by the Psychologist Registration Boards of the eight states and territories and the Australian Psychological Society (APS). The psychologist boards arguably exert the most pervasive influence on supervision standards because board registration is obligatory while membership of the APS and its specialist colleges is voluntary. The boards are vested with the statutory responsibility of translating legislative provisions into rules and regulations that govern the parameters of training and practice for any practitioner representing themselves to the public as a psychologist. Because the rules stipulate the supervision standards, supervisor characteristics, and quality control procedures used across jurisdictions in Australia, they give an indication of what the supervision of psychologists in 
Australia is like in 2007. To provide an overview of current supervision standards and procedures, we scrutinised the publicly available supervision rules and guidelines for each registration board and determined the characteristics of supervisors and key parameters of the supervision process. We also surveyed the registrars of each board to determine any impending changes to supervision rules. The responses received from representatives of each board along with the documented supervision standards are summarised in Table 1.

The most obvious recent change in boardmandated supervision rules in Australia is the introduction of mechanisms for making the competencies of supervisors more uniform and to explicitly shape the skills and knowledge of supervisors prior to the delivery of supervision. Both New South Wales (NSW) and Queensland have introduced mandatory training for psychologists acting as primary supervisors in industry-based routes to registration. Both jurisdictions require supervisors to attend a 2-day supervision training course or its equivalent to gain accreditation. The NSW course also requires the satisfactory completion of a test that assesses knowledge of the supervision process, reporting requirements, and documentation. In Queensland, supervisors are also required to submit a videotaped sample of their supervision practice for scrutiny and approval. Both NSW and Queensland require supervisors to revalidate their status over a 5-year cycle and provide evidence of ongoing supervision experience. Overall, the initiatives attempt to ensure that supervisors can instil trainee psychologists with the skills, knowledge, and ethical standards codified in the board regulations.
Although only NSW and Queensland have introduced mandatory supervisor training so far, there are indications that boards in other jurisdictions are considering this issue. As shown in Table 1, four other boards are either actively considering the introduction of mandatory training or this issue is pending review. Another relevant development is the scheduled introduction of a national professional registration scheme for health practitioners by 2008 , announced by the Council of Australian Governments. This centralisation of registration is likely to lead to greater uniformity in the skills, knowledge, and professional characteristics of psychologists providing supervision across jurisdictions.

The information presented in Table 1 also portrays some of the differences in the ways that competence to provide supervision has been operationalised. For example, the number of years of post-registration experience required before being eligible to provide individual supervision varies from 2 to 5 years. This implies that time spent practising influences the capacity of a supervisor to provide competent supervision. But, as discussed later in this article, it is not established that greater clinical experience alone ensures supervisor competence. Other variations include rules governing the eligibility of non-psychologists (e.g., social workers or psychiatrists) to be secondary supervisors (three boards permit and two prohibit this), and the extent of supervision they may provide (Table 1). Given the challenges of Australia's geography and distribution of the psychology workforce, some flexibility is needed to meet the idiosyncratic training needs of psychologists outside of urban centres that lack suitable supervisors. At present, the boards manage

Table 1. Registration Board Supervision Regulations for Australian States and Territories

\begin{tabular}{|c|c|c|c|c|c|c|c|c|}
\hline & \multicolumn{8}{|c|}{ Jurisdiction } \\
\hline & NT & QLD & NSW & ACT & VIC & TAS & SA & WA \\
\hline \multicolumn{9}{|l|}{ Supervisor characteristics } \\
\hline Years of full registration & 2 & 2 & 3 & 4 & 5 & 3 & 2 & 2 \\
\hline Special requirements & No & $\mathrm{Yes}^{\mathrm{a}}$ & Yes $^{a}$ & $\mathrm{Yes}^{\mathrm{b}}$ & $\mathrm{Yes}^{\mathrm{a}}$ & No & $\mathrm{Yes}^{\mathrm{a}}$ & $\mathrm{Yes}^{\mathrm{c}}$ \\
\hline Max. no. supervisees & 4 & $\dagger$ & $\dagger$ & 5 & 10 & 4 & 2 & 2 \\
\hline Secondary supervisors ${ }^{\mathrm{d}}$ & $\dagger$ & $<25 \%^{\mathrm{e}}$ & Yes $^{f}$ & $<10 \%{ }^{\mathrm{e}}$ & $\mathrm{Yes}^{\mathrm{f}, \mathrm{g}}$ & $\dagger$ & No & No \\
\hline \multicolumn{9}{|l|}{ Quality control } \\
\hline Current supervisor training & No & Yes & Yes & No & No & No & No & No \\
\hline Planned supervisor training & No & NA & NA & Yes & Yes & No & $\begin{array}{l}\text { Under } \\
\text { review }\end{array}$ & $\begin{array}{l}\text { Under } \\
\text { review }\end{array}$ \\
\hline
\end{tabular}

ACT $=$ Australian Capital Territory; NA $=$ not applicable; NSW $=$ New South Wales; NT $=$ Northern Territory; QLD $=$ Queensland; $\mathrm{SA}=$ South Australia; TAS $=$ Tasmania; VIC $=$ Victoria; WA $=$ Western Australia.

Notes. ${ }^{\dagger}$ Not stipulated; ${ }^{a}$ demonstration of supervision competence required; ${ }^{b} 6$ years experience required before providing group supervision; ${ }^{c}$ specialist status supervisor requirements differ; ${ }^{d}$ supervisors who provide a limited number of supervision hours, psychologists who do not satisfy eligibility criteria to be supervisors, or supervisors who may not be psychologists; ${ }^{\circ}$ of total supervision hours; ${ }^{\mathrm{F}}$ with Board approval;

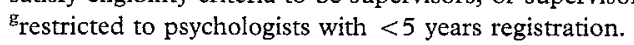


this issue by vetting potential supervision arrangements that do not conform to the standard rules.

There is more consistency across jurisdictions regarding the mandatory amount of supervision delivered across the training period. A minimum of $100 \mathrm{hr}$ of group or individual supervision is the norm and all jurisdictions require the majority of this to be individual supervision. The most common minimum amount of individual supervision is $60 \mathrm{hr}$, rising to $70 \mathrm{hr}$ in the Northern Territory and $75 \mathrm{hr}$ in Victoria. Hence, the individual supervisor-supervisee dyad is positioned at the centre of the supervision process for psychologists undergoing board-regulated training.

In summary, the statutory mechanisms for regulating the supervision of Australian psychologists are in transition. There are indications of an expanded conceptualisation of supervisor competence that is based on years of post-registration experience combined with evidence of supervisionspecific skills and knowledge. The introduction of formal training requirements reflects a move toward more direct attempts to reduce variance in the supervision provided to trainees. It remains to be seen whether the introduction of national health practitioner registration will introduce more uniformity to the supervision process.

\section{Professional regulation of supervision standards}

Although statutory regulation of the professional title and role of psychologists rests with registration boards, a substantial number of Australian psychologists voluntarily adopt membership of the APS. This body has 15,716 members (APS, 2007a) and its position on professional supervision unambiguously states that it is necessary "for all psychologists to have access to professional expertise in order to maintain excellence within the profession" (APS, $2007 b$ ). Hence, access to supervision is presented as a critical component of ongoing professional activity, not just a training requirement.

One of the main mechanisms by which APS members are compelled to demonstrate access to supervision is via the entry requirements for full membership of one of the nine specialist colleges. (Total supervision requirements for psychologists completing an APS College-approved Masters degree vary from 125 [ $1 \mathrm{hr}$ per placement day for 125 days of placement] to $180 \mathrm{hr}$, e.g., College of Clinical Psychology.) These rules primarily apply to applicants who have completed a post-graduate Masters degree in the relevant specialisation and are in the early stages of their professional career. All colleges adopt the generic APS rules governing college entry and then add various College-specific criteria. For example, for all Colleges completion of 2 years of full membership is the minimum requirement for gaining supervisor eligibility via the standard route. Thus, the positions of the APS Colleges and the registration boards reflect an implication that supervisors need clinical or practice experience to acquire the skills necessary to provide competent supervision. Although this appears a logical position, there are currently no empirical data to either support or refute the assumption.

The main difference in supervision requirements across Colleges is the minimum number of required supervision hours to move from associate to full membership status. An 80-hr threshold of professional development activities is prescribed by all Colleges, with variations in whether (and the extent that) a clinical supervision component is specified.

One of the strengths of the College-based process for supervising practising psychologists is that College-specific competencies are used as the point of reference for prescribing the skill and attitude set that is being developed. This permits a degree of specificity that cannot be achieved by the psychologist registration boards for applicants who may be seeking to practise in diverse fields from business to health-care settings. This need for the differentiation of psychologists' skills and attitudes is highlighted by the introduction of a two-tiered system for psychologists seeking to provide mental health-care services funded by the Australian government's Medicare system. Eligibility for enhanced payments is contingent on specialist psychologists demonstrating that they meet the entry requirements for the College of Clinical Psychologists. Furthermore, psychologists who achieve specialist provider status under the Medicare benefits scheme are required to demonstrate ongoing professional development (which can include clinical supervision), irrespective of whether they choose to adopt Clinical College membership. This represents a further evolution of quality control mechanisms for health-care provision, but falls short of positioning ongoing supervision as the only process by which psychologists may demonstrate their competence to practice.

\section{Ratios of supervision to applied practice}

The notion that there may be an ideal ratio between applied psychology work and supervision hours is reflected in the rules of several bodies that oversee training standards. For example, the Australian Psychology Accreditation Council rules governing the endorsement of university-based psychology training programs recommend that $1 \mathrm{hr}$ of supervision should be provided for every day spent on an applied placement during training. But the patterns are more complex at the level of the Psychologist Regulation Boards, with the boards differing in terms of their definitions of and the required ratios stipulated for part-time versus full-time trainees. 
For example, full time is defined as $20 \mathrm{hr}$ of psychology work per week in Queensland and Victoria, and as 35-40 hr per week in South Australia. Part-time work definitions vary from 15 hr of psychology work (Western Australia [WA] and Victoria) to $<25 \mathrm{hr}$ per week (Northern Territory).

Despite these varying definitions, there is some consistency in the minimum standards for frequency of supervision contact during training. The majority of jurisdictions stipulate that part-time trainees should receive $1 \mathrm{hr}$ of supervision per fortnight (although WA requires $1 \mathrm{hr}$ per week for part-time trainees). For full-time trainees the required supervision frequency is $2 \mathrm{hr}$ per fortnight for all states and territories except WA ( $2 \mathrm{hr}$ per week), NSW ( $1 \mathrm{hr}$ per fortnight), and South Australia ( $8 \mathrm{hr}$ per month).

This comparison suggests some uniformity of opinion between the APS and the registration boards regarding the role of supervision in the development of trainee psychologists. The supervisor-supervisee dyad receives the greatest emphasis and the rules suggest that the frequency and duration of supervision should be titrated to the amount of applied psychology work being conducted by the trainee. These rules are consistent with developmental models of supervision discussed further below.

This brief review of the supervision landscape for psychologists practising in Australia illustrates several emerging trends. Compulsory supervisor training in some jurisdictions reflects acknowledgment that supervisor skills cannot be assumed on the basis of years of experience alone. But there are no clear indications that compulsory supervision is going to emerge as the mechanism by which fitness to practise is determined. Instead, the broader concept of compulsory continuing professional development (which may include clinical supervision but may be limited to attendance at conferences or professional workshops) appears to be the organising framework that will be used to demonstrate that a psychologist should retain the right to offer psychological services. Given the state of the empirical literature on supervision, this broader focus on professional development is understandable. But research into supervision has the potential to further shape the development of psychology as a profession.

\section{Key lacunae in clinical supervision research}

The previous section described the supervision rules that apply to psychologists practising in diverse fields. The majority of supervision research has been conducted with psychologists practising in healthcare settings, and this literature has been adequately reviewed both internationally (Ellis, 1991; Ellis, Ladany, Krengel, \& Schult, 1996; Peake, Nussbaum, \& Tindell, 2002) and in Australia (McMahon \&
Patton, 2002; Spence, Wilson, Kavanagh, Strong, \& Worral, 2002). The following section is not a literature review, but critically comments on the strengths and weaknesses of the clinical supervision literature and highlights current gaps in clinical supervision theory and research.

\section{Need for theoretical advances}

The argument that clinical supervision research needs more theory to facilitate progress may sound paradoxical. In some respects, clinical supervision is awash with theory. Developmental theories have been around at least since the 1980 s, following the pioneering and valuable work of Stolenberg (1981). Developmental theories have several advantages: they are meta-theoretical in that they can be applied across therapeutic approaches, and offer broad principles for understanding of supervisee behaviours. But developmental theories have also been criticised as being no more than useful metaphors offering "broad brushstrokes...lacking in details and specification,... and lacking in a transition theory" (Watkins, 1995). The proliferation of developmental models (as many as 20 models were identified by Watkins, 1995) contributed little to theoretical advancement, leading authorities to call for a moratorium on more models (Borders, 1989). Additionally, many psychotherapy approaches have extended the principles, procedures and methods used for therapist-patient interactions to the supervisor-supervisee dyad, justifying the argument that there are as many theories of supervision as there are psychotherapy approaches (Bernard \& Goodyear, 2004).

Slow progress in supervision research stems from the fact that "the repeated appeals for a theoretically driven, programmatic, and empirically based approach to the practice of supervision have mostly gone unheeded" (Ellis, 1991). To advance supervision as a science, a clearer set of assumptions and postulates should be articulated, key supervision processes operationalised, and a range of predictions of how these processes will affect outcomes both for the supervisee and for the patient should be tested. Thus, theoretical refinements or new data that bridge the world of interesting but nebulous theory to practical implications at the coalface of clinical supervision practice are both necessary and overdue (Ellis et al., 1996). Some recent developments (e.g., Bennett-Levy, 2006) are promising but need to be clarified and extended by further research.

\section{Understanding the mechanisms of action}

An important milestone in the development of a mature science is the identification and explication of 
mechanisms of action. This is often demonstrated by showing that manipulation of key variables produces predicted results. Clinical supervision research currently falls well short of this benchmark and empirical tests of hypothesised mechanisms of change are rare. For example, the psychodynamic mechanisms of transference, counter-transference and parallel process have been the centrepiece of psychodynamic supervision since the 1950s (Calligor, 1981), with some authors asserting that it is "inevitable... that the supervisory relationship will become infused with the enactment of one or more of these relational configurations" (Frawley-O'Dea, 1997). But few attempts have been made to strip the conceptualisation down to its operational components (Miller \& Twomey, 1999) or to systematically manipulate these variables and determine the effects. There have been sporadic attempts at empirically analysing transference (Robiner, 1987) and reconceptualising parallel process (e.g., Grey \& Fiscalini, 1987) but these mechanisms remain poorly understood. A coordinated program of research is needed. Similar recommendations apply to other theoretical orientations including cognitive therapy. For instance, an examination of whether cognitive processes mediate the effects observed in cognitive therapy supervision is warranted in the same way that such research is being pursued to understand the effects observed in cognitive therapy (Leahy, 2004).

\section{Effectiveness of supervision}

Clinical supervision has held a central place in the training of psychologists from its early history. Survey data from coordinators of clinical programs and from supervisees demonstrate that supervision is highly regarded and positively valued (Holloway, 1984; Norcross, Hedges, \& Castle, 2002; Stein \& Lambert, 1995). These data, however, reflect no more than subjective perceptions. Important questions as to whether supervision is directly responsible for both enhancing therapist competencies and effecting better patient outcomes has been ignored or addressed in a narrow manner (Binder, 1993; Kavanagh, Bennett-Levy, \& Crow, 2002; Stein \& Lambert, 1995). Research indicating that behaviour therapy supervision produces predicted changes is preliminary and restricted to the field of developmental disability (Milne \& James, 2000). Isolated studies suggest that patients of trained and experienced therapists drop out less frequently than patients of untrained and inexperienced therapists (Okiishi, Lambert, Nielsen, \& Ogles, 2003; Stein \& Lambert, 1995). The results of a recent, controlled study demonstrating positive effects of supervision on patient outcome (Bambling, King, Raue, Schweitzer, \& Lambert, 2006) are reassuring, but "as yet there is no conclusive study linking the training of therapists to increases in competence and enhanced therapeutic outcomes with patients" (Bennett-Levy, 2006).

In Australia, psychologists-in-training receive in excess of $100 \mathrm{hr}$ of supervision before gaining full registration, and the majority of supervision occurs in a one-to-one context. Time-intensive observation methodologies such as one-way mirrors and video recording are also necessary. Given these costs, a systematic and longitudinal program of research to identify the ingredients of effective and efficient supervision is necessary and urgent. Further, the recent introduction of supervisor training in only some jurisdictions provides an excellent opportunity to research the effects of training on supervisor competencies.

\section{Lack of standardised inventories and rating scales}

A striking contrast between other domains of psychology and clinical supervision is the paucity of psychometrically validated inventories and rating scales to measure essential aspects of process and outcome. Although some notable exceptions exist in the areas of supervisory styles (Friedlander \& Ward, 1984) and working alliance (Efstation, Patton, \& Kardash, 1990), there are major gaps, perhaps none more glaring than that within supervision evaluation (Gonsalvez \& Freestone, 2007). Admittedly, some of the relevant processes reflect complex dyadic (patient-therapist) and triadic (patient-therapistsupervisor) interactions and patterns, but complexity has not impeded progress in psychopathology and personality, domains that were once considered equally elusive to pin down for accurate psychometric measurement.

\section{Supervisor assessment of trainees}

It is widely assumed that training in psychology contributes to a systematic and progressive increase in levels of expertise (from novice to expert) across the range of competencies required for professional psychology practice. Although there has recently been some progress in the definition and agreement of what these competencies might be (Falender et al., 2004; Hatcher \& Lassiter, 2007), it is unclear how these competencies factor together, what the relative sensitivity of these factors is to change, and to which specific supervision techniques (Gonsalvez \& Freestone, 2007). The lack of psychometrically validated scales contributes to this problem. Although a researcher in psychopathology has the luxury of choosing from a range of validated measures to assess levels of depression, the supervisor has few choices when it comes to selecting tools 
to assess a trainee's knowledge and skills in the many areas of clinical practice. Currently, there are no well-established instruments to measure key competencies (e.g., case formulation, skills to deal with patient resistance). It is also unclear whether and which competencies manifested in one context (e.g., child area) generalise to others (e.g., adult area), which competencies are general and meta-theoretical and which are orientation specific, and whether it is more efficient for supervisors to focus on broad meta-competencies (e.g., self-reflection) instead of a host of narrow and specific competencies (Gonsalvez \& Freestone, 2007). At present this issue is indirectly dealt with by assuming that the supervisor is aware of the competencies that the trainee must develop and so the supervisor's knowledge and clinical judgement serve as a form of criterion validity for judging whether the trainee is competent. The dearth of scales to measure therapist performance extends to all theoretical orientations. In cognitive behaviour therapy (CBT), the Cognitive Therapy Scale and its revisions (Blackburn et al., 2001; Young \& Beck, 1980) have not been widely used in CBT supervision in Australia and overseas. It is unclear whether raters require training to administer it and whether the scale is sufficiently sensitive to measure changes across the therapist's developmental stages.

Finally, it has not yet been demonstrated that the range of competencies relevant to supervision can be assessed with a satisfactory degree of reliability. In fact, preliminary research suggests that supervisor ratings are systematically biased (Borders \& Fong, 1991; Gonsalvez \& Freestone, 2007; Lazar \& Mosek, 1993; Robiner, Saltzman, Hoberman, SemrudClikeman, \& Schirvar, 1997). We need to demonstrate that supervisor ratings are both valid and reliable before we can claim a scientific status for clinical supervision. An intermediate step would be to develop, test, and refine instruments and to enhance the accuracy of supervisor judgments. Among other advantages, these developments should give supervisors confidence to carry out their roles as the profession's gate keepers and make their judgments more defensible both within the profession and in legal contexts.

\section{Evaluation of supervisors and supervision}

Evaluation in clinical supervision consists of more than the supervisor's assessment of and feedback to trainees. It includes evaluation of supervisor behaviours, the supervisory process, supervisory methods and the relevance and comprehensiveness of supervisory plans/programs for the trainee (Gonsalvez, Oades, \& Freestone, 2002; Holloway, 1984). Within Australia, accreditation standards (Australian Psychology Accreditation Council, 2007) encourage training programs to obtain supervisee feedback about supervisor performance and supervision. Even when this occurs, the power differential in the supervisor-supervisee relationship makes it likely that such feedback is systematically biased. Yet there is no evidence of a commitment to obtain systematic and unbiased evaluations of supervisor performance. This neglect means that supervisors can continue to provide supervision for many years without receiving an objective and fair appraisal, and with no way of knowing whether their self-appraisal is accurate or otherwise. This scenario is of concern especially because self-assessments may be inflated and are only modestly correlated with objective and expert judgments (Ward, Gruppen, \& Regehr, 2002). It is also hypocritical that these supervisory practices are tolerated within a profession that offers expertise in personnel appraisal and evaluation to other disciplines. In effect, while supervisors continue to encourage self-awareness and openness to critical feedback for their supervisees, the evaluation procedures they use for themselves fall well short of best practice.

The use of peer/consultant supervisors to sit in during one's supervisory sessions or having one's supervisory sessions recorded, analysed, and critiqued are strategies that deserve study. The Queensland Psychologist Registration board's requirement that supervisors submit a videotaped sample of their supervision is further indication that supervisor skills also need monitoring and evaluation. Obtaining anonymous ratings on a structured evaluation questionnaire when group supervision is conducted or having an independent agency collate several ratings before feedback to the supervisor is given (maintaining anonymity of individual raters) should be feasible but is not standard practice.

The recent emphasis on enhancing supervisor training in some Australian States follows from findings that a large proportion of supervisors $(62 \%)$ in allied health had not received training to provide supervision (Kavanagh et al., 2003). Also, the assumption that supervisors become more effective with supervisory experience is yet to be empirically established. For instance, supervisee ratings of the impact of supervision were influenced by several variables including supervisor availability, supervisor-supervisee relationship, and the use of skills training methods, but experience had no more than a weak effect (Kavanagh et al., 2003). But we need to go further than simply providing supervisors with additional training. An examination of the effects of such training programs in general and an analysis of the impact of monitoring and feedback on supervisor competence are also warranted. If competence to provide supervision is at all similar to competence to provide psychotherapy, it is likely that 
supervisors will require independent scrutiny of their actual supervision behaviour. Ultimately, the behaviour of the supervisor should lead to measurable changes in the practice of the supervisee and enhanced outcomes for the recipient of psychological services. These are issues for future research but if we are serious about the science of supervision, supervisor performance needs to be placed under more objective scrutiny.

\section{Choice of supervision methods and techniques}

Case discussions and supervisee reports of problems encountered during casework occupy a disproportionately large proportion of supervision time (Townend, Iannetta, \& Freeston, 2002), despite being supervision methods that are known to be inefficient and unreliable (Campbell, 1994) and insensitive to key competencies, including case conceptualisation, skills training and therapist-patient relationship variables (Gonsalvez et al., 2002; Holloway, 1988). The neglect of observational methods is common among CBT supervisors (Townend et al., 2002), occurs despite recommendations to the contrary by influential CBT authors (Liese \& Beck, 1997; Padesky, 1996), persists against supervisee preferences (Gonsalvez et al., 2002), and may also afflict supervisors of other theoretical persuasions (Goodyear \& Nelson, 1997).

More careful identification and clearer definition of key microskills that supervisors should target during analyses of observational methods, more systematic rationales for the choice of supervision methods (e.g., videotape vs. role-play methods), best-practice guidelines informed by pedagogical theory and empirical data (Bennett-Levy, 2006), and better training for supervisors to use these methods may help change supervision practices for the better.

\section{Self-awareness and self-reflection competencies}

Supervision addresses knowledge, skills, relationship, and attitude-value competencies (Gonsalvez et al,, 2002). In the past an important difference between therapeutic orientations was the differential emphasis placed on the four types of competencies. Recent developments suggest a trend towards more holistic approaches. For instance, new initiatives in CBT supervision have incorporated self-awareness as a relevant competency and have designed strategies to enhance the supervisees' awareness of their own thoughts, beliefs, and emotions towards their patients (Bennett-Levy, Lee, Travers, Pohlman, \& Hamernik, 2003; Linehan \& McGhee, 1994). In fact, several influential authors (Linehan \& McGhee, 1994; Padesky, 1996) have advocated the use of cognitive therapy on oneself, especially in the context of treating difficult patients such as those with complex personality disorders.

Some authors argue that certain meta-competencies such as self-reflective abilities may constitute the primary and over-arching goal of all supervision (Ronnestad \& Skovholt, 1993; Schon, 1983). Selfawareness and self-monitoring has been ranked first among 29 other different factors that may promote psychologist wellbeing and well-functioning by both professional psychologists (Coster \& Schwebel, 1997) and by training program directors (Schwebel \& Coster, 1998). Well-functioning is the flip side of professional burnout, and refers to the enduring quality in one's professional functioning over time and in the face of professional and personal stressors (Coster \& Schwebel, 1997). It is important to determine if research using objective measures of burnout, impairment and well-functioning corroborate these findings. Support for the value of such meta-competencies will have major implications for the theory and practice of clinical supervision. It will be of value to determine whether these metacompetencies are associated with improved patient and supervisee outcomes, whether there are efficient and inefficient supervision strategies to enhance selfawareness and self-reflection, and whether supervision should focus on self-awareness competencies early or later within the professional training sequence.

It is of concern that within the Australian context, a large proportion of registered psychologists and clinical psychologists may not receive ongoing supervision or peer-consulting in any systematic manner once supervision is no longer mandated by Registration bodies or APS requirements. A recent survey suggests that our international counterparts may be better placed in this regard (Townend et al., 2002). In the United Kingdom, qualified psychologists continue to receive supervision (at least infrequently) as part of ongoing self-care and professional development (Townend et al., 2002), and in New Zealand ongoing supervision is viewed as an expected component of maintaining competence to practice. This is of major concern because psychologists may be at high risk for burnout and impairment and supervision may reduce burnout and enhance wellfunctioning (Rupert \& Morgan, 2005). A systematic examination of the effects of supervision on psychologist burnout and well-functioning appears important and timely. The APS and Registration Boards may even have to consider making supervision or peer consultation an essential part of professional development, and it may be necessary to convince Governments to include receiving of supervision within the work standards prescribed for psychologists. 


\section{Need for collaborative research initiatives}

Finally, in Australia, most research on clinical supervision has, to date, been conducted by researchers affiliated with universities. Given the small cohorts of students admitted each year into postgraduate training programs, research initiatives by single universities are likely to be constrained by low statistical power, and their findings by limited generalisability. The introduction of the Medicare Benefits Scheme items for psychology services along with the impending introduction of national registration for psychologists are signs that the profession of psychology is on the cusp of significant change. Understanding the elements and processes of effective and efficient supervision has the potential to have a major impact on professional, patient, and economic outcomes for the country. For substantial progress to be achieved, research programs should be driven by Government including Psychologist Registration Boards. Additionally, collaborative research ventures among universities, and between universities and Government, are necessary to ensure that the current wave of interest in clinical supervision carries us forward and carries us far.

\section{References}

Australian Psychological Society (APS) (2007a). 2007 annual report. Melbourne: Author.

Australian Psychological Society (APS) (2007b, September). Professional practice handbook. Retrieved 9 September 2007 , from: http://www.psychology.org.aw/prac_resources/pphand book/

Australian Psychology Accreditation Council (2007). Standards for accreditation of Australian psychology programs. Melbourne: Author.

Bambling, M., King, R., Raue, P., Schweitzer, R., \& Lambert, W (2006). Clinical supervision: Its influence on client-rated working alliance and client symptom reduction in the brief treatment of major depression. Psychotherapy Research, 16, 317-331.

Bernard, J., \& Goodyear, R. K. (2004). Fundamentals of clinical supervision (4th ed.). Boston: Pearson.

Binder, J. L. (1993). Is it time to improve psychotherapy training? Clinical Psychology Review, 13, 301-318.

Blackburn, I-M., James, I. A., Milne, D. L., Baker, C., Standardt, S., Garland, A., et al. (2001). The revised cognitive therapy scale (CTS-R): Psychometric properties. Behavioural and Cognitive Psychotherapy, 29, 431-446.

Bennett-Levy, J. (2006). Therapist skills: A cognitive model of their acquisition and refinement. Behavioural and Cognitive Psychotherapy, 34, 57-78.

Bennett-Levy, J., Lee, N., Travers, K., Pohlman, S., \& Hamernik, E. (2003). Cognitive therapy from the inside: Enhancing therapist skills through practicing what we preach. Behavioural and Cognitive Psychotherapy, 31, 143-158.

Borders, L. D. (1989). A pragmatic agenda for developmental supervision research. Counselor Education and Supervision, 29, $16-24$.
Borders, L. D., \& Fong, M. L. (1991). Evaluations of supervisees: Brief commentary and research report. Clinical Supervisor, 9, 43-51.

Calligor, L. (1981). Parallel and reciprocal processes in psychoanalytic supervision. Contemporary Psychoanalysis, 18, 92-111.

Campbell, T, W. (1994). Psychotherapy and malpractice exposure. American foumal of Forensic Psychology, 12, 5-41.

Coster, J. S., \& Schwebel, M. (1997). Well-functioning in professional psychologists. Professional Psychology: Research and Practice, 28, 5-13.

Efstation, J. F., Patton, M. J., \& Kardash, C. M. (1990) Measuring the working alliance in counsellor supervision. fournal of Counseling Psychology, 37, 322-329.

Ellis, M. V. (1991). Research in clinical supervision: Revitalising a scientific agenda. Counselor Education and Supervision, 30, 238251 .

Ellis, M. V., Ladany, N., Krengel, M., \& Schult, D. (1996). Clinical supervision research from 1981 to 1993: A methodological critique. Fournal of Counseling Psychology, 43, 35-50.

Falender, C. A., Cornish, J. A., Goodyear, R., Hatcher, R., Kaslow, N. J., Leventhal, G., et al. (2004). Defining competencies in psychology supervision: A consensus statement. Foumal of Clinical Psychology, 60, 771-785.

Frawley-O'Dea, M. G. (1997). Who's doing what to whom? Supervision and sexual abuse. Contemporary Psychoanalysis, 33, 5-18.

Friedlander, M. L., \& Ward, L. G. (1984). Development and validation of the Supervisory Styles Inventory. Fournal of Counseling Psychology, 31, 541-557.

Gonsalvez, C. J., \& Freestone, J. (2007). Field supervisors' assessments of trainee performance: Are they reliable and valid? Australian Psychologist, 23, 23-32.

Gonsalvez, C. J., Oades, L. G., \& Freestone, J. (2002). The objectives approach to clinical supervision: Towards integration and empirical evaluation. Australian Psychologist, 37, 68-77.

Goodyear, R. K., \& Nelson, M. L. (1997). The major supervision formats. In C. E. Watkins (Ed.), Handbook of psychotherapy supervision (pp. 328-344). New York: John Wiley.

Grey, A., \& Fiscalini, J. (1987). Parallel process as transferencecountertransference interaction. Psychoanalytic Psychology, 4, 131-144.

Hatcher, R. L., \& Lassiter, K. D. (2007). Initial training in professional psychology: The practicum competencies outline. Training and Education in Professional Psychology, 1, 49-63.

Holloway, E. L. (1984). Outcome evaluation in supervision research. Counseling Psychologist, 12, 167-174.

Holloway, E. L. (1988). Instruction beyond the facilitative conditions: A response to Biggs. Counselor Education and Supervision, 27, 252-258.

Kavanagh, D. J., Bennett-Levy, J., \& Crow, N, (2002). A cognitive-behavioural approach to supervision. In $M$. McMahon, \& W. Patton (Eds.), Supervision in the helping professions: $A$ practical approach (pp. 131-142). Frenchs Forest, NSW: Pearson.

Kavanagh, D. J., Spence, S. H., Strong, J., Wilson, J., Sturk, H., \& Crow, N. (2003). Supervision practices in allied mental health: Relationships of supervision characteristics to perceived impact and job satisfaction. Mental Health Services Research, 5, 187195.

Lazar, A., \& Mosek, A. (1993). The influence of the field instructor-student relationship on evaluation of students' practice. Clinical Supervisor, 11, 111-120.

Leahy, R. (2004). Contemporary cognitive therapy: Theory, research and practice. New York: Guilford.

Liese, S. B., \& Beck, J. S. (1997). Cognitive therapy supervision. In C. E. Watkins (Ed.), Handbook of psychotherapy supervision (pp. 114-133). New York: Wiley. 
Linehan, M. M., \& McGhee, D. E. (1994). A cognitivebehavioural model of supervision with individual and group components. In S. E. Greben (Ed.), Clinical perspective on psychotherapy supervision (pp. 165-188). Washington, DC: American Psychiatric Press.

McMahon, M., \& Patton, W. (Eds.). (2002). Supervision in the helping professions. Frenchs Forest, NSW: Pearson Education Australia.

Miller, L., \& Twomey, J. E. (1999). A parallel without a process: A relational view of a supervisory experience. Contemporary Psychoanalysis, 35, 557-580.

Milne, D., \& James, I. (2000). A systematic review of effective cognitive-behavioural supervision. British foumal of Clinical Psychology, 39, $111-127$.

Norcross, J. C., Hedges, M., \& Castle, P. H. (2002), Psychologist conducting psychotherapy in 2001: A study of the Division 29 membership. Psychotherapy: Theory, Research, Practice, Training, 39, 97-102

Okiishi, J., Lambert, M. J., Nielsen, S. L., \& Ogles, B. M. (2003). Waiting for supershrink: An empirical analysis of therapist effects. Clinical Psychology and Psychotherapy, 10, 361-373.

Padesky, C. A. (1996). Developing cognitive psychotherapist competency: Teaching and supervision models. In P. $M$ Salkovskis (Ed.), Frontiers of cognitive therapy (pp. 266-292). New York: Guilford.

Peake, T. H., Nussbaum, B. D., \& Tindell, S. D. (2002). Clinical and counseling supervision references: Trends and needs. Psychotherapy: Theory, Research, Practice, Training, 39, 114 125

Robiner, W. N. (1987). An experimental inquiry into transference roles and age. Psychology and Aging, 2, 306-311.

Robiner, W. N., Saltzman, S. R., Hoberman, H. M., SemrudClikeman, M., \& Schirvar, J. A. (1997). Psychology supervisors' bias in evaluations and letters of recommendation. Clinical Supervisor, 16, 49-72.
Ronnestad, M. H., \& Skovholt, T. M. (1993). Supervision of beginning and advanced graduate students of counselling and psychotherapy. Foumal of Counselling and Development, 71, 396-405.

Rupert, P. A., \& Morgan, D. J. (2005). Work setting and burnout among professional psychologists. Professional Psychology: Research and Practice, 36, 544-550.

Schon, D. (1983). The reflective practitioner: How professionals think in action. . New York: Basic Books.

Schwebel, M., \& Coster, J. S. (1998). Well-functioning in professional psychologists: As program heads see it. Professional Psychology: Research and Practice, 29, 284-292.

Spence, S. H., Wilson, J., Kavanagh, D., Strong, J., \& Worral, L. (2001). Clinical supervision in four mental health professions: A review of the evidence. Behaviour Change, 18, 135155.

Stein, D. M., \& Lambert, M. J. (1995). Graduate training in psychotherapy: Are therapy outcomes enhanced? fournal of Consulting and Clinical Psychology, 63, 182-196.

Stoltenberg, C. (1981). Approaching supervision from a developmental perspective: The counselor complexity model. fournal of Counseling Psychology, 25, 59-65.

Townend, M., Iannetta, L., \& Freeston, M. H. (2002). Clinical supervision in practice: A survey of UK cognitive behavioural psychotherapists accredited by the BABCP. Behavioural and Cognitive Psychotherapy, 30, 485-500.

Ward, M., Gruppen, L., \& Regehr, G. (2002). Measuring selfassessment: Current state of the art. Advances in Health Sciences Education, 7, 63-80.

Watkins, C. E., Jr. (1995). Psychotherapy supervisor and supervisee: Developmental models and research nine years later. Glinical Psychology Review, 15, 647-680.

Young, J., \& Beck, A. T. (1980). Cognitive therapy scale: Rating manual. Unpublished manuscript. Philadelphia, PA: Center for Cognitive Therapy. 